\title{
Endodontic Management of Acute Dental Pain Among Pregnant Patients
}

\author{
Salman Ashraf Khan ${ }^{1}$ \\ Arooj Ul Hassan ${ }^{2}$ \\ Zunaira Iqbal ${ }^{3}$ \\ Mohammad Hassan ${ }^{4}$
}

\author{
BDS, FRACDS \\ BDS, MPH \\ BDS, MCPS, MPH \\ BDS, MSc, PhD
}

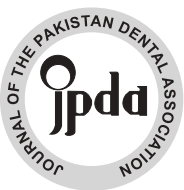

OBJECTIVE: The purpose of this study is to reinforce the safety of non-surgical endodontic treatment in the management of acute dental pain of pulpal origin in pregnant patients in all trimesters.

METHODOLOGY: The study was conducted amongst pregnant females with acute dental pain. Pain of endodontic origin in 273 pregnant patients was managed by performing non-surgical root canal treatment. Percentages were calculated as descriptive statistics to have a comparison of preferred treatment by dentists for acute pain management during pregnancy. One Way ANOVA was used to explore the difference between treatment selection plans.

RESULTS: From the total sample of 273 participants, there was no significant difference found between the selection of endodontic treatment and Trimesters $(\mathrm{F}(2,270)=.79, \mathrm{p}=.45)$ same results were obtained for the analgesics prescription during pregnancy and the trimesters during pregnancy $(\mathrm{F}(2,270)=1.41, \mathrm{p}=.24)$. On the other hand, the difference between the prescription of antibiotics during 1st, 2nd and 3rd trimesters was found which was statistically significant $(\mathrm{F}(2,270)=12.38$, p> .001). Endodontic treatment was completed on 251 (91.6\%) pregnant patients to relieve the acute dental pain whereas only $22(8.4 \%)$ patients did not undergo endodontic treatment in pregnancy. Among the cases who had endodontic treatment, $75.4 \%$ of cases were dealt with in the second trimester of pregnancy. The recommendation of antibiotics was less. In the entire data, antibiotic prescription was seen in the second trimester of pregnancy, whereas, overall, antibiotic prescription was at minimal level. Analgesic prescription was found to be $(44.1 \%)$ in practice among pregnant participants during the treatment.

CONCLUSION: Non-Surgical Endodontic Treatment is a safe and reliable treatment option for the management of restorable teeth with acute pain of pulpal origin in pregnant patients. Dentists should not be reluctant in prompt invasive dental management in these patients if indicated.

KEYWORDS: pregnancy, pain, dental treatment, endodontic treatment

HOW TO CITE: Khan SA, Hassan AU, Iqbal Z, Hassan M. Endodontic management of acute dental pain among pregnant patients. J Pak Dent Assoc 2021;30(1):7-11.

DOI: https://doi.org/10.25301/JPDA.301.7

Received: 24 July 2020, Accepted: 07 December 2020

\section{INTRODUCTION}

$\mathrm{E}$ mergency dental treatment during pregnancy, in case of need, is frequently met with reluctance from majority of dentists in our society. Pregnancy, a physiologic state causes many changes in the patient and these changes affect the overall health of a pregnant female. ${ }^{1}$ Many changes affect physiology, i.e. anatomical changes,

1. Assistant Professor, Head of Department, Department of Operative Dentistry, Dental Hospital University of Lahore.

2. PhD Scholar, Assistant Professor, Head of Department, Department of Community \& Preventive Dentistry, Dental Hospital University of Lahore.

3. Registrar, Department of Operative Dentistry, Dental Hospital University of Lahore.

4. Assistant Professor, Department of Prosthodontics, Dental Hospital University of Lahore.

Corresponding author: "Dr. Zunaira Iqbal” < zunaira9466@ gmail.com > biochemical changes. A dentist must know about these changes before treating pregnant patients otherwise it can lead to serious complications if proper precautions are not taken. ${ }^{2,3}$ As far as the physiology of cardiovascular system is concerned, heart rate is elevated in pregnancy ${ }^{4}$, Supine Hypotension Syndrome ${ }^{5}$, headache in 1st and 2nd trimester ${ }^{4}$, anemia ${ }^{5}$, increased respiratory rate ${ }^{6}$, etc. Gastrointestinal changes are also very common in pregnancy. ${ }^{7}$ Changes in the hormonal level can change the growth of the gingiva which can lead to gingival hyperplasia. ${ }^{8,910}$ Some common problems like tooth decay and enlarged gingiva are aggravated due to increased vomiting in first trimester due to acid attack on the tooth structure. According to American Pregnancy Association, second trimester is the ideal time to treat minor dental problems and cleaning of the teeth by 
a professional to treat infections. ${ }^{11}$ Some antibiotics and analgesics can be safely prescribed by the dentist, but only as an adjunct to operative management. ${ }^{12}$ According to the Food and Drug Administration (FDA), among five different groups (A, B, C, D and X) of medication for patients, category $\mathrm{B}$ is the safest to use in pregnant patients. ${ }^{13}$ It includes Penicillin and Cephalosporins group, Azithromycin, Erythromycin and Clindamycin as they do not show any harm to the developing fetus. As far as analgesics are concerned, Acetaminophen is recommended for dental treatment during pregnancy. Local anesthetic like $2 \%$ Lignocaine with 1:100,000 Adrenaline is also safe during pregnancy if needed. ${ }^{14}$

Due to the physiological and anatomical changes, oral health of the pregnant patient can worsen which is usually neglected by the patient. Studies also provide evidence that dentists tend to defer urgent dental care of pregnant patients. ${ }^{15}$ So, there is a need to educate the dental practitioners that pregnant state generally does not predispose a patient to be medically compromised. ${ }^{16,17}$ For this reason, it is essential for dental health professionals to provide pregnant patients with appropriate and timely oral health care. ${ }^{18}$

\section{METHODOLOGY}

\section{Study Setting:}

This was an interventional study which was conducted in Operative Dentistry department, Dental Hospital, The University of Lahore after taking approval from the institutional ethical committee (UCD/ERCA/16/09). Sample Size: This study was done by using non-probability consecutive sampling technique. The sample size of 273 patients was calculated using OpenEpi software by taking the prevalence of deferring from dental treatment of pregnant patients as $23 \%$ population proportion ${ }^{19}, 95 \%$ Confidence Interval and 5\% margin of error.

\section{Inclusion Criteria:}

Pregnant female patients with an age ranging from 18 to 42 years were included as sample of the study.

\section{Exclusion Criteria:}

Any pregnant patient with established co-morbidities or a history of miscarriage was not included.

\section{Clinical Procedure:}

All the patients were attended and treated by a single practitioner/researcher following the same protocols to better assess the efficacy of the intervention. The patients were diagnosed by taking history and intra-oral examination including peri-apical X-ray as an investigation tool with protective measures such as thyroid collar and lead apron. A total of 273 patients were treated by non-surgical root canal treatment after acquiring informed consent. For optimal pain control, local anesthesia (Lignocaine $2 \%$ with 1:100,000 Adrenaline) was given in all patients using aspirating syringes by slow injection technique in Inferior Alveolar Nerve block (up to 2 minutes). Rubber dam isolation was used as a standard of care in all patients. Working length determination was done with the use of electronic apex locator followed by peri-apical radiograph with appropriate protection. Chemo-mechanical preparation was achieved with Sodium Hypochlorite 3\% (Parcan by Septodont, Saint-Maur-des-Fossés, France) and 19\% EDTA in gel form (Ethylenediaminetetraacetic acid, MD-Chelcream by Meta Biomed Co. Ltd. Chungbuk, Korea) irrigation. Pre-obturation smear layer removal was done with $17 \%$ EDTA solution (MD-Cleanse by Meta Biomed Co. Ltd. Chungbuk, Korea) Glide path was established using manual K files. Shaping of study canal was done using manual or rotary Nickel Titanium ProTaper (by Dentsply Sirona, Ballaigues, Switzerland) file systems. The canals were appropriately enlarged based on the vitality status and the initial canal size. Vital teeth were preferably treated as a single visit endodontic procedure. In non-vital teeth, $\mathrm{Ca}(\mathrm{OH})_{2}$ (calcium hydroxide, Calcipex by Nippon Shika Co. Ltd., Shimonoseki, Japan) intra-canal medicament was generally placed for two weeks prior to obturation. Interim restoration given was zinc oxide based (Coltosol by Coltene, Altstätten, Switzerland) After the criteria for obturation was met, obturation was done with the cold lateral compaction technique using master gutta percha cone of the corresponding size and accessory gutta percha points using Calcium Hydroxide based sealer (Sealapex by Kerr,California, USA). Post obturation chamber cleaning and residual sealer removal was done using ethanol-soaked cotton pellets. Composite (Ceram.X SphereTEC by Dentsply Sirona, Ballaigues, Switzerland) was used as a final restorative material of choice after etching (32\% phosphoric acid, Scotchbond Universal etchant by 3 M ESPE, St. Paul, USA) and bonding (ESPE Single Bond Universal by $3 \mathrm{M}$ ESPE, St. Paul, USA)

The patients were contacted at 1 month and 3 months intervals for follow up and to identify any complications related to the treatment.

\section{STATISTICAL ANALYSIS}

Statistical analysis was performed using SPSS version 22. Percentages were calculated as descriptive statistics to have a comparison of preferred treatment by dentists for acute pain management during pregnancy. As inferential statistics, 
One-way ANOVA was used to get the difference between the treatment selection preferences of dentists for the management of acute dental pain during pregnancy (trimester wise).

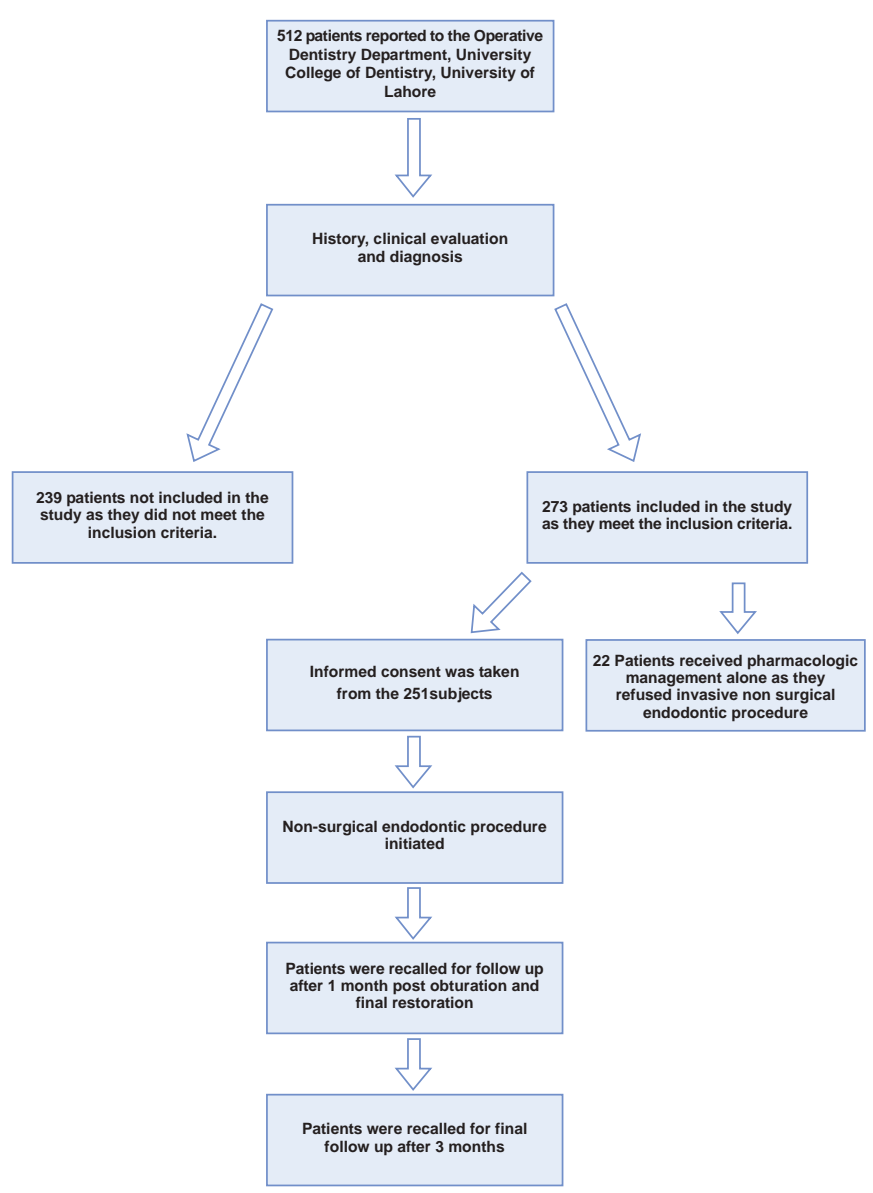

Diagrammatical representation of the procedure followed in the study for patient induction

\section{RESULTS}

The results revealed that there was no significant difference found between the selection of endodontic treatment and Trimesters $(\mathrm{F}(2,270)=.79, \mathrm{p}=.45)$ same results were obtained for the analgesics prescription during pregnancy and the trimesters during pregnancy $(\mathrm{F}(2,270)=1.41, \mathrm{p}=.24)$. On the other hand, the difference between the prescription of antibiotics during 1st, 2nd and 3 rd trimesters was found which was statistically significant $(\mathrm{F}(2,270)=12.38, \mathrm{p}=.000)$ which means that the ratio of antibiotics prescription was different in 1st, 2nd and 3rd trimesters.

To get the pairwise comparison, Post Hoc, Tukey test, was performed on antibiotic prescription during pregnancy as this difference was found significant. The results revealed
Table 1: Difference between treatment selection preferences of dentists for acute dental pain management among pregnant patients

\begin{tabular}{|c|c|c|c|c|c|}
\hline & & Mean & Std. Deviation & $\mathbf{F}$ & Sig. \\
\hline & First Trimester & .86 & .35 & & \\
\hline \multirow[t]{3}{*}{ Endodontic Treatment } & Second Trimester & .92 & .26 & .79 & .45 \\
\hline & Third Trimester & .92 & .26 & & \\
\hline & First Trimester & .44 & .50 & & \\
\hline \multirow[t]{3}{*}{ Analgesics Prescription } & Second Trimester & .41 & .49 & 1.41 & .24 \\
\hline & Third Trimester & .56 & .50 & & \\
\hline & First Trimester & .36 & .48 & & \\
\hline \multirow[t]{2}{*}{ Antibiotics Prescription } & Second Trimester & .75 & .43 & 12.38 & .000 \\
\hline & Third Trimester & .74 & .44 & & \\
\hline
\end{tabular}

Table 2: Pairwise comparison of antibiotic prescription during pregnancy

\begin{tabular}{|c|c|c|c|c|}
\hline & (I) Trimester-(J) Trimester & Mean Difference (I-J) & Std. Error & Sig. \\
\hline \multirow{3}{*}{ Antibietics preseription } & $1^{k}$ Trimester- $2^{\text {2ul }}$ Trimester & -.39114 & .07919 & .000 \\
\hline & $2^{\text {st }}$ Trimester $-3^{\text {td }}$ Trimester & .00866 & .07653 & .993 \\
\hline & $3^{\text {red }}$ Trimester- $1^{\text {w }}$ Trimester & $.38248^{\circ}$ & .10187 & .001 \\
\hline
\end{tabular}

that during 2nd trimester of pregnancy, antibiotics were prescribed to most of the patients with acute dental pain whereas no statistically significant difference was found for the prescription of antibiotics during 2 nd and 3rd trimester. Contrary to this, it was found and was statistically significant that during 3rd trimester of pregnancy, the antibiotic prescription was more as compared to the antibiotic prescription during 1 st trimester.

The graph given below explained the dentists' preferred endodontic treatment for acute pain management among pregnant patients as compared to the prescription of analgesics and antibiotics.

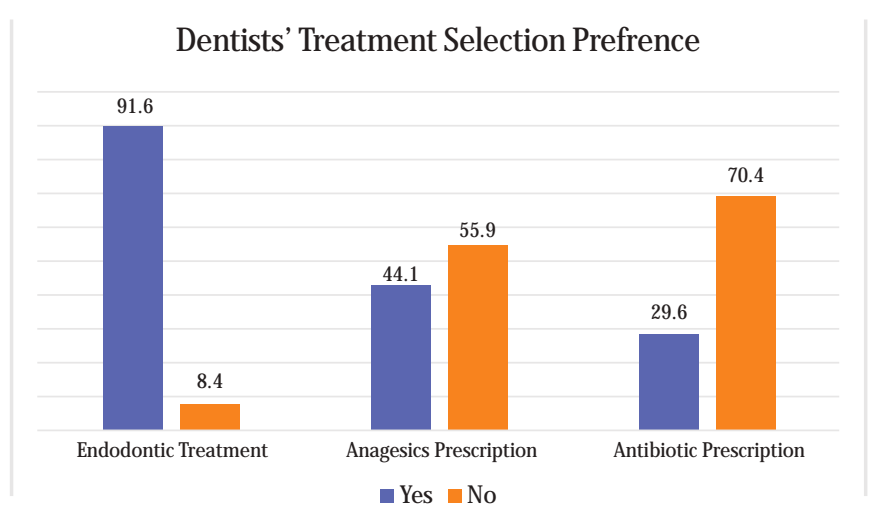

\section{DISCUSSION}

Recent evidence shows that dental practitioners generally have a lack of knowledge regarding pregnant patients and are reluctant to treat these patients specially in the first trimester. According to the American Dental Association (ADA) guidelines "preventive, diagnostic and restorative 
dental treatment is safe throughout pregnancy". The dentists and gynecologists both need to reinforce mutual liaison and emphasize the patient regarding timely management of acute dental pain, if needed. The dentists and the gynecologists both also need to play their role in provision of routine preventive oral healthcare to the patients. ${ }^{20}$

The American Dental Association in collaboration with the American College of Obstetricians and Gynecologists developed a consensus statement in 2012 that was reaffirmed in 2019 which emphasizes the role of dentists in treatment of oral infections as a part of healthy pregnancy. ${ }^{21}$ NonSurgical Endodontic treatment for management of acute dental pain is also considered safe and the treatment of choice where indicated. Center for Disease Control (CDC) also warns about the misuse of pain medications in pregnancy and its deleterious effects on the fetus. ${ }^{22}$ The guidelines provided by the contemporary textbooks also suggest that endodontic treatment is not a contraindication in pregnancy and the use of drugs should be in accordance with the safety and health of the patient and fetus. ${ }^{23}$ It is imperative that the dentists treat these patients promptly and explain the importance of timely care.

Maintenance of oral health is an integral part of a healthy pregnancy. During this physiological phase the female body goes through many hormonal changes which may affect the oral health. One of these changes is increased carbohydrate consumption specifically in the third trimester which can increase chances of plaque formation and dental decay. ${ }^{24}$

Increased levels of estrogen and progesterone increase the permeability of oral vessels and reduce immunocompetence during pregnancy, increasing the chances of severe oral inflammation. These changes can lead to increased caries risk and gingival enlargement which can cause pulpal and periodontal harm. ${ }^{25}$

Severe odontogenic infections in pregnancy may have dire consequences. Dental practitioners may be reluctant to treat orofacial infections invasively in pregnancy due to the false assumption of potential risk to the fetus. This also concerns to radiographic evaluation and pharmacologic therapy. It potentially leads to self-medication leading to delay in optimal management, which can be very harmful for the mother and fetus and can lead to complications. ${ }^{26}$

A study conducted by Wali et al concludes that dentists have a general deficiency in knowledge regarding the management of pregnant patients and are reluctant to treat them. This study also revealed that many dentists consider treatments other than scaling and root planning to be relatively unsafe in pregnant patients. Most of the dentists were unaware of the evidence-based guidelines regarding the treatment of pregnant patients. The study recommends that dentists broaden their perspective and knowledge to provide evidence- based oral health care to the pregnant patients. ${ }^{27}$

In this study the researchers performed Non-Surgical Endodontic Treatment on more than 250 pregnant patients and followed up on their dental status and overall health for up to 3 months. All elective dental procedures should be avoided during pregnancy but if acute dental pain management like Non-Surgical Endodontics is indicated, should not be deferred. Neglect or delay in prompt treatment can lead to life threatening conditions. ${ }^{28}$ This study showed that endodontic treatment is safe in pregnancy and it should not be delayed even in the first and third trimesters.

\section{CONCLUSION}

Non-Surgical Endodontic Treatment is a safe and reliable treatment option for the management of restorable teeth with acute pain of pulpal origin in pregnant patients. Dentists should not be reluctant in prompt invasive dental management in these patients if indicated.

\section{CONFLICT OF INTEREST}

None to declare

\section{REFERENCES}

1. Ajay G Nayak, Oral Health Considerations for the Pregnant Woman, Dental Update 2012; 39:51-54.

https://doi.org/10.12968/denu.2012.39.1.51

2. Dental Considerations in Pregnancy-A critical Review on the oral care.j clin Diagn Res 2013;7:94

3. Adina Bosca L. Assessment of Dentists' Knowledge Concerning the Management of Pregnant Women in the Dental Office. Biomedical J Scientific \& Technical Research. 2019;15.

https://doi.org/10.26717/BJSTR.2019.15.002667

4. Sanghavi M, Rutherford JD. Cardiovascular physiology of pregnancy. Circulation. 2014;130:1003-08.

https://doi.org/10.1161/CIRCULATIONAHA.114.009029

5. Kurien S, Kattimani VS, Sriram RR, Sriram SK, VK PR, Bhupathi A, et al. Management of pregnant patient in dentistry. J Int Oral Health: JIOH. 2013;5:88.

6. Costantine M. Physiologic and pharmacokinetic changes in pregnancy. Frontiers in pharmacolog. 2014;5:65.

https://doi.org/10.3389/fphar.2014.00065

7. Wald A, Van Thiel DH, Hoechstetter L, Gavaler JS, Egler KM, Verm R, et al. Effect of pregnancy on gastrointestinal transit. Dig Dis Sci. 1982;27:1015-18.

https://doi.org/10.1007/BF01391748 
8. Srivastava A, Gupta KK, Srivastava S, Garg J. Massive pregnancy gingival enlargement: A rare case. J Indian Soc Periodontol. 2013;17:503-06. https://doi.org/10.4103/0972-124X.118324

9. Boggess, K. A., Urlaub, D. M., Massey, K. E., Moos, M. K., Polinkovsky, M., Matheson, M. B., Lorenz, C. Oral hygiene practices and dental service utilization among pregnant women. J Am Dent Assoc, 2010;141:5:553-61. https://doi.org/10.14219/jada.archive.2010.0228

10. Pina PM, Douglass J. Practices and opinions of Connecticut general dentists regarding dental treatment during pregnancy. Gen Dent. 2011;59:e25-31.

11. Al Habashneh R, Guthmiller JM, Levy S, Johnson GK, Squier C, Dawson DV, et al. Factors related to utilization of dental services during pregnancy. J Clin Periodontol 2005;32:815-21. https://doi.org/10.1111/j.1600-051X.2005.00739.x

12. Michalowicz BS, DiAngelis AJ, Novak MJ, Buchanan W, Papapanou PN, Mitchell DA, et al. Examining the safety of dental treatment in pregnant women. J Am Dent Assoc. 2008; 139:685-95. https://doi.org/10.14219/jada.archive.2008.0250

13. Giglio JA, Lanni SM, Laskin DM, Giglio NW. Oral health care for the pregnant patient. J Can Dent Assoc. 2009;75:43-8. PMID: 19239743.

14. Ouanounou A, Haas DA. Drug therapy during pregnancy: implications for dental practice. Br Dent J. 2016;220:413-7. PMID: 27103292.

https://doi.org/10.1038/sj.bdj.2016.299

15. Gaffield ML, Gilbert BJ, Malvitz DM, Romaguera R. Oral health during pregnancy: An analysis of information collected by the pregnancy risk assessment monitoring system. J Am Dent Assoc 2001; 132:100916 .

https://doi.org/10.14219/jada.archive.2001.0306

16. Pina PM, Douglass J. Practices and opinions of Connecticut general dentists regarding dental treatment during pregnancy. Gen Dent. 2011;59: e25-31.

17. Bobetsis YA, Barros SP, Offenbacher S. Exploring the relationship between periodontal disease and pregnancy complications. J Am Dent Assoc. 2006;137: S7-S13.

https://doi.org/10.14219/jada.archive.2006.0403

18. Nasir A, Asghar S, Ahmed S, Rashid E, Ikram S, Moin F. Knowledge of Dentists Regarding Dental Treatment During Pregnancy in Karachi. Pak Oral Dent J. 2017;37:137-41.
19. Strafford KE, Shellhaas C, Hade EM. Provider and patient perceptions about dental care during pregnancy. J Matern Fetal Neonatal Med 2008; 21:63-71. https://doi.org/10.1080/14767050701796681

20. Oral Health Care During Pregnancy Expert Workgroup. 2012. Oral Health Care During Pregnancy: A National Consensus StatementSummary of an Expert Workgroup Meeting. Washington: National Maternal and Child Oral Health Resource Center, Georgetown University. www.cdph.ca.gov/programs/MCAHOralHealth/ Documents/MCAH-OHP-OralHealthPregnancyConsensus2011.pdf. Accessed Oct. 1, 2020.

21. American College of Obstetricians and Gynecologists. Oral health care during pregnancy and through the life span. Committee Opinion No. 569. Obstet Gynecol. 2013;122:417-22.

https://doi.org/10.1097/01.AOG.0000433007.16843.10

22. Interrante, JD, Ailes, EC, Lind, JN, Anderka, M, Feldkamp, ML, Werler, MM, Taylor, LG, Trinidad, J, Gilboa, SM, Broussard, CS, and the National Birth Defects Prevention Study. Risk comparison for prenatal use of analgesics and selected birth defects, National Birth Defects Prevention Study 1997-2011. Ann Epidemiol. 2017 https://doi.org/10.1016/j.annepidem.2017.09.003

23. Hargreaves, K. M., Cohen, S., \& Berman, L. H. (2011). Cohen's pathways of the pulp. St. Louis, Mo: Mosby Elsevier.

24. Razi S, Muhammad SG, Rashid H. Dental Considerations in a Patient with Pregnancy: A Concise Review. J Pak Dent Assoc 2016; $25: 48-52$

25. Patil SN, Kalburgi NB, Koregol AC, Warad SB, Patil S, Ugale MS. Female sex hormones and periodontal health-awareness among gynecologists-A questionnaire survey. The Saudi Dent J. 2012;24:99104

https://doi.org/10.1016/j.sdentj.2011.12.001

26. Tocaciu S, Robinson BW, Sambrook PJ. Severe odontogenic infection in pregnancy: a timely reminder. Aus Dent J. 2017;62:98101.

https://doi.org/10.1111/adj.12463

27. Wali A, Siddiqui TM, Sarwar A, Anjum A, Rao H. Perception and understanding of dental practitioners in provision of dental treatment to pregnant women in Karachi, Pakistan. Indian J Dent Sci 2016; 8:199-204.

https://doi.org/10.4103/0976-4003.196816

28. Wazir S, Khan M, Mansoor N, Wazir A. Odontogenic fascial space infections in pregnancy-a study. Pak Oral Dent J. 2013 1;33. 